\title{
Study on the Characteristics of Chinese Mulao Traditional Sports Culture and Its Project Classification
}

\author{
Lichun Wei \\ College of Sport \\ Hechi University \\ Yizhou, China
}

\begin{abstract}
Mulao is an agricultural nation with a long history of cultural tradition, and they live with clan as unit, keeping a strong clan blood relationship. Mulao traditional sports activities is the important part of its culture, and it has profound historical and cultural value for the research on traditional sports of ethnic minorities in our country. In the process of modernization, it is the most important to explore and arrange Mulao traditional sports and make systematic research, maintain the characteristics of Mulao traditional sports culture, and carry forward its excellent culture. This paper studies the characteristics of Mulao traditional sports culture and its project classification by means of literature, field investigation and interview. The results show that Mulao traditional sports culture has the characteristics of folk custom, social organization, nationality, region, fitness and entertainment etc, and its project classification includes fitness and entertainment, athletics, performance, children's games and so on.
\end{abstract}

Keywords-Mulao; traditional sports culture; characteristics; project classification

\section{INTRODUCTION}

Mulao is a mountainous ethnicity with small population in our country, mainly live in Mulao Autonomous County of Luocheng to the south of Jiuwan Mountains in the north of Guangxi, with a total of 112.8 thousand Mulao people, and others scattered in Xincheng, Yishan, Liucheng, Du'an, Huaijiang, Hechi and other counties, living together with Zhuang, Han, Yao, Miao, Dong, Maonan, Shui and other ethnicities. Mulao is of Sino-Tibetan language family, and of Zhuang-Dong language group, so most of them cap speak Chinese and some also can speak Zhuang language. It has no its own national language, generally uses Chinese.

Mulao people create a lot of material civilization and spiritual civilization in their long-term production and life, and maintain a valuable wealth for the human, of which national

Fund Project:

1. The Humanities and Social Sciences Research and Planning Fund Project of Annual Ministry of Education in 2016, Project No: 16XJA890002

2. The western task of 2016 National Philosophy and Social Science Fund Project, Project No.: 16XTY002

3. The special project for project construction of the awarding institute of Hechi University Master degree in 2016, Project No.: 2016LG011 traditional sports is one. Most of these folk traditional sports activities are not carried out independently or separately, often combined with the production and life, especially with the festival activities, giving a healthy, funny and lively atmosphere for ethnic life. According to incomplete statistics, Luocheng Mulao Autonomous County has more than 40 traditional sports of ethnic minorities, of which some are derived from the folk custom, such as the Mulao straw (cloth) dragon dance, lion dance and cockfighting, especially the dragon playing has more ethnic characteristics. When the dragon is playing, people will largely set off firecrackers and "burn dragon", praying for happiness to the dragon god, for disaster elimination, for favorable weather and good harvest in the next year; while lion dance has a variety, and especially the single-horn griffin is the most typical, whose head is like a eagle head, but has one horn, and the dance is fierce. Unlike other ethnic dance, the lion dance team also plays sword and stick and plays boxing, with more appreciative features. Cockfighting also has a strong entertainment, and its rules have quite ethnic characteristics; people use "water" to measure time and judge the win or loss, reflecting the people's creativity as well as positive and healthy attitude towards life. There is also the unique "Dong" social organizations (a unit under the family) originated from the Mulao ethnicity, such as Dazhujiao (playing lime powder bag), most held on the "Hui Kuan" sacrifice day (May 5), and the game method is to sew a small bag of 5-cun diameter with mosquito net cloth, place lime powder in it, hang it at about 40 meters from the shooting point; the contestants aim the powder gun at the target, and if power flies out of the bag, the shooting wins. For the winner in the first shot and the second shot, will be awarded pig's foot, and the winner in the later shots will be awarded 2-liang pork, till the prize of 10-jin pork is issued completely. Some Mulao activities of scrambling for glutinous rice cake, Mulao bamboo ball, bamboo connecting ball, etc reflect the national unity, harvest celebration and family harmony. The folk performance includes elephant's step and tiger's palm, phoenix protecting eggs, playing peg-top and rolling bamboo ring and so on 


\section{THE CHARACTERISTICS OF MULAO TRADITIONAL SPORTS CULTURE}

\section{A. The Characteristics of Folk Custom}

Folk custom refers to the unique folk culture of a region or ethnicity. Mulao has its main traditional festivals including Yifan Festival, Spring Festival, Zoupo Festival, Ancestral Festival, Anlong Festival and so on. Yifan festival is the grandest Mulao traditional festival, having deep impression of ancient LuoYue culture, which currently has been listed among the non-material cultural heritages by the State Council to get effective protection and heritage. Yifan festival is also known as "Yifan Gong Ye" and "Xi Le Yuan", and its main purpose is to make a votive prayer for the "ancestors' wish". Yifan festival has different time according to the place, surname and "Dong", but most hold it three times every ten years. The "four -dong" surnamed Zhongshiyin hold it at the year of Mao, Wei and Hai, the "five-dong" at the year of Chou, $\mathrm{Yi}$ and Qiu, and the "two-dong" surnamed Wu in Dawu Village at the year of Mao, Wei and Hai. It is said the reason is the different actual conditions in different area and it also may be to provide convenience for the clansmen returning back for festival celebration. The days all are the auspicious days after the beginning of winter, and taking "Dong" as unit, people held grand "Yifan platform" in the ancestral hall of their own clan to carry out devout sacrifice activities. Spring Festival, called "Da Nian" in Mulao word, is also an important festival of Mulao, which is influenced by the spread of Han culture. Zoupo is also a grant festival similar to the Yifan festival. The difference among the three is in the content of activities, the Yifan festival mainly focuses on the sacrifice activities, supported with the unique performance of masters; the Spring Festival takes the "straw dragon dance" and "cockfighting" for the climax, with the subject of praying for happiness and for disaster elimination as well as making entertainment and meeting friends; and the Zoupo, held at the Spring Festival and Mid-Autumn Festival, is a festival of nubile young men and women to sing folk songs on the slope field, passing emotions by songs and looking for a bosom friend.

As an important part of these festivals, traditional sport not only enriches the connotation of festive activities, but also makes the festival more healthy and plentiful both in the content and the form. At the same time, the sports activities in the traditional festivals will have more vitality along with the development of ethnic festivals, and will be continued by generation after generation. For example, in recent years, the relevant departments of the government developed and arranged some traditional sports project with Yifan festival as the theme, such as "scrambling for glutinous rice cake and Mulao bamboo ball, to ceremoniously launch them in the Yifan festival, which not only enrich the festival culture, but also provide the evidence for traditional sports reflecting the national history and culture. At the same time, the mutual dependence between ethnic traditional sports and traditional festivals is also conducive to the development of both. "Straw dragon dance" and "cockfighting" in the Spring Festival is also the Mulao conventional traditional sports activities. By these, we can see that all these festivals highlight the Mulao characteristics of folk custom.

\section{B. The Characteristics of Social Organization}

Mulao clan has very strong concept, which is reflected by that all the main surnames of Mulao almost have its "Dong" social organization. "Dong" is essentially a feudal clan organization, a big clan branch. Almost each "Dong" in the main surnames of Mulao sets up "Dong Temple", and some large surnames also build "ancestral temple". Both "Dong Temple" and "Ancestral Temple" have a group in charge of affairs, which is called "head of Dong ".’Dong Temple" generally holds a large party every year, known as the "Hui Kuan", which is purposed to discuss the major affairs of the whole major clan and also plays a role in maintaining the order of social production. Among them, the surname "Zhongshiyin" also holds the shooting competition activities on the "Hui Kuan" day of May 5th (lunar calendar) each year, known as "Dazhujiao (playing lime powder bag)". This activity comes down in one continuous line of the Mulao hunting activities, which forms a unique ethnic traditional activity. Hunting on the mountains is to obtain prey to satisfy the hunger of hunting people, but to prevent the disoperation from beasts, which is an essential activity of agricultural people to protect the crop harvest. For a long time, Mulao people have the habit of "hunting on mountains". Before the Spring Festival and till the Lantern Festival every year, the men of many villages, in a group of ten or eight families, thirty or fifty people, respectively take their hound, carry powder gun, sword and spear, go to the mountains for hunting. And the purpose of this activity is to prevent the crops from being eaten by birds and beasts. The Mulao people have their residence surrounded by mountains, and their many fields are scattered in the valleys and ditches, so "hunting on mountains" is important as you can imagine. These activities fully demonstrate the social organization of the Mulao people, as well as their strong national concept.

\section{The Characteristics of Nationality}

Nationality is the main symbol of a national culture different from another national culture, belonging to the scope of national cultural attributes. The human creates culture, while culture cultivates and shapes the human itself, and under the influence and restriction of various factors, it is difficult for the human to create the culture of the same pattern. "Human creates different types and different patterns of culture while they shape themselves into a group with different cultural characteristics, that is the nation." Mulao people create the Mulao culture in its unique environment, condition, manner and way, so as to make the culture have its national characteristics, which is fully reflected in the cultural material and spirit, thus they have had the relatively stable material production style, lifestyle, behavior norm, social organization, living habits, language and thinking methods, art forms, sports activities, and values. Just these stable cultural characteristics shape the nation that is the so-called national characteristics.

The reason why a nation forms, most fundamentally depends on the formation of its own unique culture. The sports culture of national village is based on the national culture as the background, and the national village sports created by the Mulao in the northwest Guangxi through a long-term production and life reflects the distinctive national character in 
its content and form. Speaking of the Mulao ethnic sports, we must say " scrambling for glutinous rice cake, Mulao bamboo ball, "straw dragon dance", "cockfighting" and so on are Mulao unique national sports, and with the development of history, these items have deep impression of history and culture of Mulao, they symbolize and represent Mulao, showing strong nationality of Mulao.

\section{Regional Features}

A region is a place where a great number of people may live and develop for a long time, due to the influences of diverse geographical environments, the ethnic minorities in various regions have formed traditional sports with characteristics of their own, colorful and unique. Mulao people mainly live in South China such as Guangxi, where there stand hills and peaks, high and bizarre, but few lands applicable for farming, main crops include rice, corn, sweet potato and wheat, etc. So corn and rice are staple foods for the Mulao people besides, rice is often processed into glutinous rice cake which can be seen in almost every family, so a "scrambling for glutinous rice cake" event came into being. The glutinous rice cake is a mascot of Mulao people on Yifan Festival, for the people there believe that the more they scramble for the food, the more they get the luck. In the meantime, the region where Mulao people live is in a low altitude in Guangxi, it is close to a tropical ocean to the east, hilly areas of Nanling stands to the north, and Yungui Highland stands to the west. There are many rivers running through the region, and the geographical conditions are complicated there. With the integrated effect of solar radiation, general atmospheric circulations and underlying surfaces, the climate there takes on a long day in summer but short in winter, which is suitable for planting, therefore folk activities such as Straw Dragon (made of straw for dancing) and Bamboo Stem Ball Game (made of bamboo for playing) came into being.

\section{E. Features of Fitness and Entertainment}

Traditional sports activities of Mulao people aim at body building, having characteristics of entertainment and physical exercise. Most of the activities are arranged in their spare time to celebrate harvests, festivals, congratulate on weddings, leisure and recreation, and the sports are integrated to the entertainment, showing fully an atmosphere of cheerfulness. Villagers there are very fond of body building activities such as water bucket playing and clew windings and so on, which are accompanied with singing, dancing and performances, all of styles are simple, full of thick body building features and happy atmosphere. Mulao people are one of the ethnic minorities across China, having simple and natural folk customs. During busy seasons, the people participate in the plowing and farming; during slack seasons, they raise poultries, engage in weaving and aquaculture. It seems that most of traditional sports activities only appear in the form of body building and amusements, which potentially meet traditional culture featuring "contentment is enough for happiness" and "taking what comes" in the country. So most of the sports activities in villages are body building games, folk games and chesses, enjoying a sense of snatching a little leisure from a busy life and showing scenes of ease and harmony of the people.

\section{CLASSIFICATION OF SPORTS}

In order to well grasp the generality of traditional sports events of Mulao people during the development and keep up with the social development, according to the value and functions of the traditional sport events, they are classified into four parts: first, traditional sports events which aim at playing and entertainment; second, traditional sports events which are shown via competitive abilities; third, traditional sports events which aim at regional and sacrificial performances with sacrifice, festivals and traditional customs as carriers; forth, traditional sports event which aim at body building.

\section{A. Entertainment and Body Building}

Traditional sports events which aim at playing and entertainment are aiming at amusement, exercises and entertainments in spare time which are done under some modes, and they are an important part of the folk entertainment of the Mulao people, and also interesting activities in folk amusements, which are frequently seen, the simplest and most common. Main features are the co-existence of amusement and competitiveness, which aim at entertainment, recreation and playing, and main purposes are to self pleasing, and needing no superb skills, strong to adaptability, and the players there may release their emotions. Main amusements include courtyard games played by children (such as strength games (elephant step and tiger palm), chicken head games, water carrying game (Da Shui Tong) and Fei Cai), adult games (chicken game, bird game), teen and adult shared brain games (Mulao Three-Piece Chess, Ku Dang Chess, Six-Piece Chess, Five Elements Chess, Three-Six-Nine Chess) and so on. The playing and entertainment-oriented traditional sports of Mulao people are a positive and participatory entertainment, which need no audiences but involvement, and every player shall be devoted wholeheartedly in order to get fun, such sports are easy to popularize, and the people can directly get pleasant emotions and physical exercises in the events. Though the activities have rules, yet they are not strict, aiming at the purposes of playing and entertainment. The activities are not in the pursuit of physical difficulty or desires to win, differing from competitive sports games, through the activities the players just enjoy playing in a relaxed form, though they will win or lose, yet whether to win or to lose is not the purpose, what they want is an emotional adjustment, physical and mental happiness, which have functions such as educating teenagers, adjusting the public life, enhancing the group consciousness and cultivating the collective spirits.

For example, Mulao people advocate chess playing, which is popular there. The chess playing is also called Lei Qi (namely playing chess) or Nei Qi (Dong Qi, Jian Qi and Zou Qi). It has an extensive mass base, after meals, during slack seasons, when resting at fields, the people will gather at the village entrances, roadsides, fields or sitting at home or below tree shadows to play the games so as to refresh, relieve pressure and please themselves. Before chess, I-go, military chess and jumping chess were introduced to the Mulao people, there were six traditional chesses among the Mulao people, including Mulao Three-Piece Chess, Mother-Son Chess, $\mathrm{Ku}$ Dang Chess, Six-Piece Chess, Five Elements Chess, ThreeSix-Nine Chess, of which, the Five Elements Chess and $\mathrm{Ku}$ 
Dang Chess, due to few pieces, are easy to understand and learn, popular in children. The Three-Six-Nine Chess is mainly learned by children through teaching by adults, which is interesting, funny and unique, and every one of the Mulao people knows it, all can self teach and play one round or more. Of which, the Five Elements Chess chessboard consist of two squares which are crossed vertically, there are 12 places for pieces to move to, and two players hold four pieces each. The piece moving shall follow five moves as per the five elements (metal, wood, water, fire and earth), when the "earth" meets the piece of the other opponent, whose piece there will be captured. Before the formation of completing the five elements, each player is allowed to move one piece and one square each round (piece movement), the chess result will cause no dogfall, most of which are defeated or abortive. The $\mathrm{Ku}$ Dang Chess, also called "Gang" chess, got its name due to its shape like crotch. It will be played by two players, each holds two pieces on two sides, and the one who boxes up the other is the winner, however, most end in a draw, which is popular in children.

\section{B. Competitive Sports}

Traditional sports, which are mainly shown through competitive skills among Mulao people, are physical activities where players aim to win under certain rules through individual or collective sports competing in physical strength, brain and skills. Traditionally Mulao people have diverse and colorful sports with a long history, which can be traced back to the collection, hunting and training of tribal occupation skills by ancestors in ancient times. At present, traditional sports activities of Mulao people are mainly carried out on holidays and religious sacrifices festivals. Seen from the number of participants, there are individuals who show off skills of their own or two players who cooperate to play, or many people to play, according to the nature and form of manifestation, it is classified into physical strength, intelligence and skills. Traditional competitive sports of Mulao people include bamboo balls, bamboo ball, grass ball, flames ball, rolling briquettes, horse riding, climbing blade staircase, scrambling for glutinous rice cake, grabbing dragon beads, plowing racing, grabbing grain bags, rush harvest, near racing and so on. With the launching of nationwide sports games, the competitive sports of Mulao people have been making a rapid progress. For example, the bamboo ball racing, one of the folk village sports activities, originated from the production and life, owning rich ethnic characteristics and having a higher value of exercises and entertainment. The bamboo ball, also known as bamboo stem ball, is one of the unique folk village sports activities among the Mulao people. Since the early Qing Dynasty up to now, about three hundred years have passed, and its historical traits of long spread have turned out that it is full of strong vitalities, and deeply popular in the Mulao people. In 1998, the sports was awarded the first prize of performance at the Guangxi 9th Ethnic Sports Games held at Guigang, Guangxi; and won the first prize of performance at the National 6th Ethnic Sports Games held in Beijing in 1999. Afterwards till 2013 the folk sports activity had been continued, which was just a little lowered in popularity.
Scrambling for glutinous rice cake is one of the unique village sports activities among Mulao people in the northwest of Guangxi, which is a collective cultural activity integrating Shamanism, sacrifice and amusement, and it plays an extremely important role in uniting villages and developing the sports culture of Mulao people. The "Scrambling for glutinous rice cake" is the most cheerful activity for the Mulao people, three players will form a group, totaling 3 groups, and they take long chopsticks to scramble for the three-cornered Chinese rice-pudding placed in tile crocks by turns, however, the three players have to share three feet on the ground totally, depending on hand in hand, foot in foot, jumping while balancing. If anyone loses the balance, the rice-pudding that he/she gets will fall on the ground, at the moment, the audients around will be cheering together with drum beating and yelling one after another, till the glutinous rice cakes in the crocks all are gone, and the group which gets the most glutinous rice cakes will be the winner. Three-cornered Chinese ricepuddings are mascots on Yifan Festival for the Mulao people who believe that the more they get the rice-puddings, the more they get the happiness.

\section{Performance}

When people feel good, they express the most excited thoughts and feelings through "gesticulating with hands and feet". The sports musical dance in combination with performance, entertainment and arts express the inner feelings of Mulao people. It enables people to appreciate the fullbodied national customs and brings them strong appeal and enjoyment of beauty through unique forms, strong dynamism, dance with distinctive rhythm and colorful folk costume.

As a means of Mulao people to inherit ethnic sports culture, the sports musical dance derives from the worship of dragon and lion, primitive religion, ancestor worship and polytheism. Pleasant singing and tap-tap dance steps form the scene of gaiety in festival. Group dancing does not accompany with musical instruments. The rhythm is controlled by singing or drumbeat and footstep. Group dancing has vigorous dancing posture and lively rhythm. Song and dance of Mulao people is random to celebrate successful harvest, worship nature and ancestors. The group dancing mainly has straw dragon dance and lion dance for Mulao people to express thoughts and feelings and inward world. The dance accompanied by music of Mulao people integrates psychological needs, emotional impulse and body movement beneficial to physical and mental health. The number of participants and the degree of emphasis are beyond the reach of any traditional item. Different from the dances in other areas, the sports musical dance of Mulao people lays emphasis on orderly ranks, uniform movement, strong lineup and allegoric modeling and symbolic actions and expression. People exchange thoughts and feelings, recreate and keep fit by singing and dancing joyously. The sports musical dance of Mulao people creates an entertainment atmosphere with abundant ideological contents for people and invigorates health of Mulao people effectively.

For example, straw dragon dance is one of the activities of Mulao people during the Spring Festival, combining physical exercise with recreational activities. Reputedly, when teenagers see adults make cloth dragon to celebrate the Spring 
Festival, they are incompetent to make cloth dragon for dragon dance, so they weave straw dragon with straw. According to the folklore, it is initiated by teenagers in Dizhoutun of Xiaochangan Town. They weave straw dragon to parade through the village in the evening of Chinese New Year's Eve and burn the straw dragon by accident. It has unique appeal for youngsters to dance with the "fiery dragon". Afterwards, adults cannot help weaving straw dragon. Therefore, the straw dragon dance becomes a physical activity of the whole village. As physical activity of Mulao people in northwest Guangxi, the straw dragon dance is social, ethnic, practical and interesting and becomes more appealing imperceptibly. The beautiful clothes glorify it. Except for functions of social interactions and entertainment, the straw dragon dance can temper people's willpower, improve sensitivity and physical quality and train decisive, firm and persistent, self-confident and positive, noble character and sentiments.

\section{Games}

Games include elephant step and tiger palm, bamboo ring rolling, Dajitou, Chezhuhu, Dashuitong and Feicai. "Dazhujiao (shooting lime powder bag)" is a shooting contest. People use mosquito netting to sew a packet with diameter of about 5-cun filled with lime powder and hang it in the place about four meters away from the shooting site. Participants wear splendid attire and carry powder gun and bags filled with potassium nitrate and iron sand to gather at the competition terrain. The person officiating at the ceremony issues an order: game commences. Participants take their places in the shooting site and shoot. People win when the powder flies off the lime bag. The incentive measure is also interesting: the first and the second ones are awarded with pig's knuckle. Winners can get two liangs of pork until the 10 -jin of pork are distributed (The prize is the sacrifice).

\section{CONCLUSION}

The sports culture of Mulao people is created through longterm labor and life, deep-seated in the folk with extensive mass basis. The culture inherited and formed through thousands of years will not be integrated or replaced. Instead, it will integrate with the process of globalization. With rich traditional customs and popularity among people, even the smallest culture will not be eliminated. But it will decline and disappear as time goes by. We hope it can continue impressively. Although the traditional sports culture of Mulao people is an important part of Mulao culture, improvements in implementation and popularization are required. Mulao people shouldn't forget it in the development of ethnic culture. Instead of understanding culture from the perspective of collectors, they should inherit and carry forward traditional culture with utility purpose and let culture serve modernization and national rejuvenation. The development of Mulao culture must depend on traditional sports and emphasize ethnic characteristics. The functions of traditional sports must be expanded for construction of culture and service of economic development of Mulao people. With continuous development and improvement of Mulao civilization, the colorful sports culture of Mulao people will be everlasting and magnificent in Chinese culture.

\section{REFERENCES}

[1] Zhang Ping, Wang Su, Ye Guichen. Research on Traditional Sports of Mulao People [J], Sports Culture Guide, 2008, (8)

[2] Mo Yanting, Ma Qiang. Research Overview on Domestic Mulao People since the Reform and Opening-up [J], Center for Studies of Minorities in Northwest China, 2015 (5)

[3] Sun Shaoning. Research on Tourism Value of Sports of Mulao People [J], Bulletin of Sports and Technology, 2011, (6)

[4] Li Minggang. Investigation and Research on Current Situation of Traditional Sports Culture of Gelo People in Guizhou [J], Scientific Consult, 2010(05): 45

[5] Zhao Yunpeng, Bai Bing. Research on Traditional Sports Culture of Minorities in Guangxi Province $[\mathrm{J}]$, Liaoning Sport Science and Technology, 2010, 30(1): 70-71

[6] Fang Diansheng, Wang Gongfa, Xiao Shuiping. Research on Sports Culture of Mulao People under the Background of International Tourism Island Construction [J], Journal of Harbin Institute of Physical Education, 2011, (3): 37-39

[7] Jia Jianjun. Research on Inheritance of Traditional Ethnic Sports Culture in Tianshui City of Gansu Province [D], Lanzhou: School of Physical Education of Northwest Normal University, 2011

[8] Li Jian. Research on Feasibility of Taking Traditional Sports of Mulao People as Contents of Sunshine Sports Activities for Middle School [D], Guilin: School of Physical Education of Guangxi Normal University, 2011

[9] Fang Diansheng, Xiao Shuiping. Thinking on the Development of Traditional Sports of Mulao People under the Perspective of International Tourism Island [J], Sport Science and Technology, 2011(3):17-19

[10] Zong Xuefei. Research on the Source of Traditional Sports of Mulao People and the Inheritance of Mulao Culture in the Development [J], Journal of Beijing Sport University, 2005, 28(9): 1189-1191

[11] Zhu Jianguo. Review and Trend of Development of National Minorities' Traditional Sports Meeting [J], Liaoning Sport Science and Technology, 2010, (2): 73-76

[12] Wang Gang. Attention to Traditional Ethnic Sports: Current Situation, Problems and Thinking [J], Journal of Capital Institute of Physical Education, 2008, (2):1-4

[13] Zhang Ying, Jin Yiping. Current Situation and Development Direction of Traditional Ethnic Sports of Our Country [J], China Sport Science, 2012, 22(4): 31-32

[14] Zhang Xuanhui, Liu Tao, Guo Yingzhi. Reconstruction of Modernization of Traditional Ethnic Sports [J], Journal of Chengdu Sport University, 2008, (2): 11-13

[15] Wu Yi, Li Runzhong. Humanistic Connotation and Cultural Quality Education of Traditional Sports of Mulao People [J], Journal of Qiongzhou University, 2010, 17(2): 87-92

[16] Xu Caitong. Discussion on Modernization Transformation of Traditional Ethnic Sports in Our Country [J], Journal of Wuhan Institute of Physical Education, 2008, (4): 61-64

[17] Wang Cuie. Discussion on Traditional Sports of Mulao People in Guangxi [J], Relics from South, 2005, (1): 105-107 